\title{
Identifying the Effectiveness of Active Learning Strategies and Benefits in Curriculum and Pedagogy Course for Undergraduate TESL Students
}

\author{
Jamila Shaaruddin, Maslawati Mohamad \\ Faculty of Education, National University of Malaysia (UKM), Bangi, Malaysia \\ Email: jamila_shaaruddin@yahoo.com.my
}

How to cite this paper: Shaaruddin, J., \& Mohamad, M. (2017). Identifying the Effectiveness of Active Learning Strategies and Benefits in Curriculum and Pedagogy Course for Undergraduate TESL Students. Creative Education, 8, 2312-2324. https://doi.org/10.4236/ce.2017.814158

Received: September 20, 2017 Accepted: November 25, 2017 Published: November 28, 2017

Copyright $\odot 2017$ by authors and Scientific Research Publishing Inc. This work is licensed under the Creative Commons Attribution International License (CC BY 4.0).

http://creativecommons.org/licenses/by/4.0/ (c) (i) Open Access

\begin{abstract}
The teachers nowadays are trained properly, competently enough, excel academically with high grades but still considered as "incapable" or "unfit" to teach. There are still many problems and weaknesses among young graduates, despite the initiatives taken by the government to address the issue. The adoption and practice of active learning approaches into the component of course design offered in higher institutions is a common practice nowadays and is crucial in addressing these weaknesses among our young graduates. This case study identifies the effectiveness of active learning strategies and benefits in curriculum and pedagogy course which is a central concept of student-centred learning, derived from the constructivist approach. This article aims to ensure the course efficacy by integrating active learning to support their practice of active learning brought to learners by micro teaching, peer-reflections/feedbacks and self-reflections. Data were collected from documents in a form of e-reflections in ifolio and telephone interviews via WhatsApp Mobile Phone application. This qualitative study reports in detail the experience of 10 undergraduate students. The findings reveal the effectiveness of the three commonly used strategies associated with active learning strategies in this study. Among the beneficial of imparting active learning strategies are as follows; creates positive learning environment, allows direct interaction between lecturers and students, promotes open minded ideology, learn to respect someone else opinion, enhance communication skill, allows students to personally engaged with the learning activities and encourage participation. The findings and discussion of this study would be able to help the pertinent parties such as policy maker, teachers, facilitators and students with better guidance for utilising and maximizing different other selections of active learning strategies
\end{abstract}


that could benefit teaching and learning process in the higher education sce-

nario.

\section{Keywords}

Active Learning, Micro Teaching, Peer-Reflections/Feedbacks, Self-Reflections, Curriculum and Pedagogy

\section{Introduction}

Education acts an important tool in the effort of preparing Malaysia as a developed country by year 2020. It serves as a vital foundation in providing and supplying skillful human resources needed to boost the growth and development of a country. The government has been taken several strategies in its effort to improve the quality of our education system (Chamhuri \& Abdul-Mumin, 2011).

Among the strategies are to continuously revise the curriculum to ensure that it is in line with the needs of the country and the changes that are taking place in the education system around the world. Many scholars believe that active learning has a positive influence on student learning outcomes. Improving the quality of education deals a lot with the betterment of the teaching and learning process, well-planned curriculum and effective implementation of the curriculum (Abdullah \& Hui, 2014).

As stated in the Malaysia Education Blueprint 2013-2025 (MOE, 2012), there are many new approaches that have been introduced in improving the efficacy of teaching and learning strategies which includes using inquiry learning, contextual learning, constructivism and mastery learning.

For the past several years, active learning has become an alternative option to traditional teaching methods and received considerable attention. Fisher (2010) asserted a cause of concern arise due to the limitation of the traditional classroom in supporting these learning approaches. Yahyazade et al. (2014) in a recent research claimed that the students learn more when active learning is compared to traditional teaching methods (such as lecture), regardless of the subject matter. Besides that, the students tend to enjoy the class more and able to retain the information longer. The researchers also claimed that active learning allows students to learn in the classroom with the help of instructor and other students, rather than learning on their own.

Therefore, this study aims to identify the effectiveness of active learning strategies used in curriculum and pedagogy course employed by a group of undergraduate TESL students. The researchers explore the benefits of active learning strategies used in curriculum and pedagogy course.

\section{Literature Review}

\subsection{Active Learning}

Edgar Dale (1969) proposed the Cone of Learning (Figure 1) and emphasised 


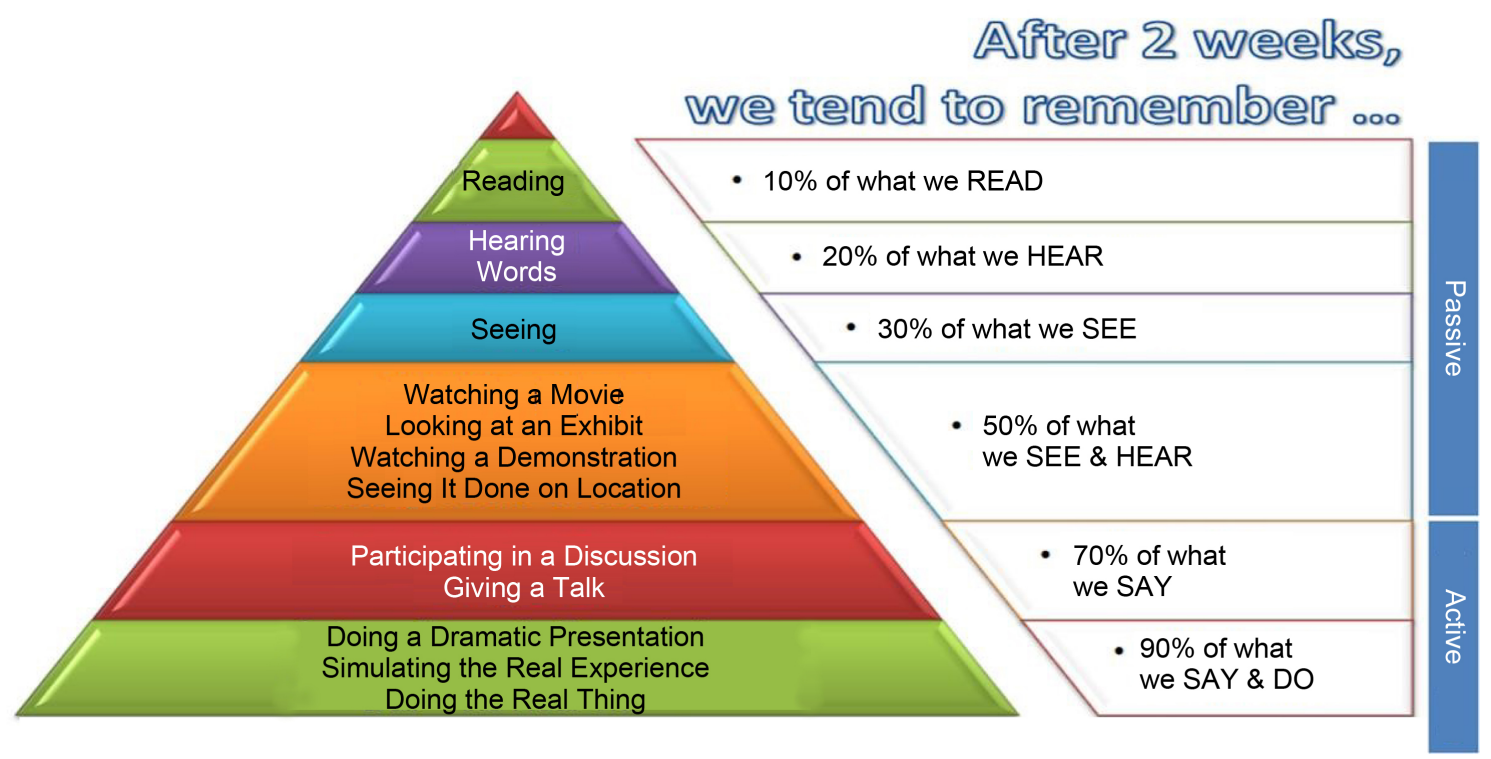

Figure 1. The cone of learning. Source: Adapted from E. Dale, Audio visual methods in teaching, 1969, NY: Dryden press.

that the active learning approach will help students to remember about $70 \%$ $90 \%$ of what they have learnt, even after two weeks. This active learning approach involves activities such as group discussions, presentations, simulations and tutoring. In contrast, students who are only involved in passive activities such as lectures, viewing arts, graphs and maps can only retain about $10 \%-30 \%$ of what they had learnt.

In the process of making the learning experience enjoyable, the integration of active learning tasks is much appreciated as mentioned by Močinić (2012). The study by Freeman et al. (2014) affirmed the importance of learning more about how class time was used and how students perceived the impact of active strategies on their learning. According to Tedesco-Schneck (2013) the introduction of active learning acts as a path to critical thinking in promoting students' involvement in classroom activities

Active Learning Strategies: Microteaching, Peer-Reflections/Feedbacks, Self-Reflections

Research findings by (Ingersoll \& Strong, 2011) mentioned that microteaching is effective for prospective teachers in helping them to improve in set induction, multiple frames of reference as well as observation skills. There was a high correlation between micro-teaching performance and subsequent teaching performance. The usage of microteaching among prospective English teachers in English teacher education is also recommended due to its advantages. For this study, microteaching can be considered as an important subject to prepare these students for their teaching practice.

It is undeniable that prospective teachers do perceived microteaching as an important subject or course (Zakaria \& Ah'hyat, 2010; Fernandez, 2010). Zakaria \& Ah'hyat (2010) further continued and claimed that students possessed positive 
attitude towards micro teaching as it increases their level of self-confidence in such of friendliness and equanimity environment (Remesh, 2013). According to Ismail (2011) the inclusion of microteaching created a positive impact among ESL student teachers' in their teacher training programs that also affect awareness and views with regards to their language and teaching competencies. Ghanaguru et al. (2013) highlighted that the young and mostly inexperienced beginner teachers will be better prepared to face the challenges in teaching profession confidently through the use of microteaching and the significance of practical knowledge that linked their experiences to content knowledge. Mahmud and Rawshon (2013) further mentioned that microteaching can play a significant role in student education which can lead to the contribution towards understanding better the process of learning and its complexities.

Meerah et al. (2010) claimed that in improving students learning, feedback plays an important role. Peer reflection also refers as peer evaluation, review, assessment and feedback. Shiu et al. (2012) believe that peer evaluations reduced free riding among peers and find that students had generally positive attitudes about peer evaluations. Tahir (2012) stated that when conducting peer review, students feel less pressure and feel more relax. The students claimed that the advices given by peers are very easy to be used specially to revise essay and consider it as very useful. The students are able to engage with more practices and discussions are made among friends through peer review. Strijbos \& Sluijsmans (2010) highlighted that peer assessment is an educational arrangement that stimulates the students to reflect and provide feedbacks on their peers, discuss and collaborate among themselves

Self-reflection according Norberg (2014), help students to construct new and deeper understanding of the experience learnt. It can also improve personal and professional awareness. Toros \& Medar (2015) claimed self-reflection promotes constructing new meanings and solutions. As also improves personal and professional awareness and professional growth from learning through experiences. Langley \& Brown (2010) mentioned that reflective journaling allows students to recognize and record their strengths and weaknesses. It involves an intensely personal process that deals with them in a safe environment.

\subsection{Blended Learning in Higher Institutions in Malaysia}

The study of hybrid courses in higher education conducted by local scholars such as Dzakiria et al. (2012) suggested that blended learning provides a pedagogical alternative that could play a significant role. It also has a lot of potential and offered a comfortable middle ground in the system of higher education in Malaysia.

Azizan (2010) concluded that with the utilization of technology in physical classrooms, it offers and provide extra resources for the students which later leads to enhancement in learners' confidence and competence as well as improving the learning quality. 
However, this research defines blended learning as the facilitation of teaching and learning process using a combination of blending face to face ( $\mathrm{f} 2 \mathrm{f})$ and online methods.

\section{Research Methodology}

\subsection{Research Setting and Participants}

The participants for this study consisted of TESL students selected because they have fulfilled the criteria that suited the aim of this case study. They were ten third year undergraduate TESL students registered in the Faculty of Education, National University of Malaysia (UKM) and required to enroll in Curriculum and Pedagogy Course. The selection of participants was carried out based on purposive sampling who had fulfilled the required criteria. This is also in accordance to the researchers' intention to select participants and sites in order to understand the central phenomenon (Creswell, 2014: p. 206).

\subsection{Research Instruments}

The students submitted documents in a form of e-reflections tasks in ifolio. The responses from the students' e-reflections in ifolio were utilised and telephone interviews via WhatsApp Mobile Phone with the participants were conducted.

In this study, the e-reflections were written and prepared individually and compiled as a group task as suggested by Creswell (2014: p. 223) that mentioned documents as a good source for text (word) data. Not only it provides valuable source of information but also as being the language and words of the participants for a qualitative study.

Each group uploaded their written e-reflections within 5 - 6 pages, submitted to the lecturer, who is also one of the researchers. The e-reflections were later evaluated. The total marks for e-reflections represented 10 percent. Marks were given to ensure that the respondents prepared comprehensive documents Creswell (2014: p. 217).

The usage of qualitative interviews is in accordance to Yin (2011: pp. 134-135) suggested that the researcher should have a mental framework of the study questions that does not try to adopt any uniform behavior or demeanor. He further continued; preferably using participants' choice of own words during the discussion of the topic. Creswell (2014: p. 219) further recommended telephone interviews due to geographically dispersed and the inability of the researcher in this study to come to a central location for an interview. The interview questions were recorded using WhatsApp Mobile Phone application since it is easily accessible by the researcher. Then, it was sent via WhatsApp Mobile Phone application to the participants and recorded their responses. After that, the recorded interviews were sent back to the interviewer using the same mobile applications.

\subsection{Curriculum and Pedagogy Course Objectives}

The integration of active learning among TESL students in Malaysia education 
scenario. Apart from that, at the National University of Malaysia, it is compulsory for any second year TESL student to take, attend and complete a course namely Curriculum and Pedagogy. The aim is to provide students with knowledge on the meaning of curriculum planning and implementation. The content includes teaching plan; namely the preparation and implementation of the semester, weekly and daily lesson plans; and teaching techniques in the classroom. Bloom's Taxonomy and creative and critical thinking skills (CCTS) are also discussed. Students will also be exposed to several approaches of studentcentred learning, application of ICT in teaching and classroom management. These theories will be applied in the Micro Teaching sessions that focus on specific teaching skills.

The course activities require total Teaching and Learning Hours of 120 hours. The students attended 20 hours of lecture and 16 hours of activity simulation. They are also required to submit e-reflections Tasks in i-folio which consists of 19 hours, apart from which, 30 hours of Teaching Preparation and 35 hours of Self-directed Learning.

The evaluations consist of these items and the weightage for examination is 40\%, Task (Daily Lesson Plan) contributes 20\%, Microteaching 30\% and Reflections (Group) 10\%.

\section{Findings and Discussion}

\subsection{Effectiveness of Active Learning Strategies Used by the Students}

The findings on the effectiveness of active learning strategies used by the participants are discussed in three sub-sections identified from the study: micro teaching, peer-reflections/feedbacks and self-reflections.

\subsubsection{Microteaching}

This study confirmed the claim made by Fernandez (2010) that students perceived microteaching as important subject or course Zakaria \& Ah'hyat (2010) as the participants mentioned as follows:

“... I think microteaching is really important" (G2) and

"what I get from the microteaching session was a lot." (G2-P4)

According to Ismail (2011) the inclusion of microteaching created a positive impact among ESL student teachers' in their teacher training programs that also affect awareness and views with regards to their language and teaching competencies. Zakaria \& Ah'hyat (2010) further continued and claimed that students possessed positive attitude towards micro teaching as it increases their level of self-confidence in such of friendliness and equanimity environment (Remesh, 2013). The response below confirms the previous studies:

... It increases one confident ( $G 1)$

... helps us to improve our confidence (G3) and

... It increases one confident and teaching quality towards the end of the semester $(G 2-P 4)$ 
Ghanaguru et al. (2013) highlighted that the young and mostly inexperienced beginner teachers will be better prepared to face the challenges in teaching profession confidently through the use of microteaching and the significance of practical knowledge that linked their experiences to content knowledge. Mahmud and Rawshon (2013) further mentioned that microteaching can play a significant role in student education which can lead to the contribution towards understanding better the process of learning and its complexities. The responses below confirm their previous studies:

"Next, it could help the students of the course to have expectation of what could happen during teaching and learning session" ( $G 1$ )

"It serves as practice for novice teachers before enter the real situation of teaching" (G1)

"let us future teachers to get ourselves into the real situations and know how to deal with the students in the classroom" (G2)

"it allows us future teachers to be able to familiarize ourselves with the teaching practice in the classroom... you'll be able to know how you are going to handle the students in the classroom" (G2)

"prepares us real life situation... most importantly help us to prepare the lesson beforehand... enhance our teaching skill” (G3)

\subsubsection{Peer Reflection/Feedback}

The findings of this study supports previous study by Meerah et al. (2010) that claimed in improving students learning, feedback plays an important role as it stimulates the students to reflect and provide feedbacks on their peers, discuss and collaborate among themselves (Strijbos \& Sluijsmans 2010). The responses by the participants confirm the study as follows:

"I think it is really important because with peer reflection you'll be able to know ... what kind of ...elements or ...characteristics that you need to improve in the... classrooms... for you to be able to teach... better" (G2)

“... their opinion is very important because... you see... our friends, our peers know us and their feedbacks help us a lot" (G3)

“... it can help us fix our performance and teaching skills." (G3-P2)

Shiu et al. (2012) believe that students had generally positive attitudes about peer evaluations as the responses by the participants confirm the study:

“... if their friend made mistakes... they could point it out without having a fight afterwards and ...allows students to work professionally among them besides having good relationship with one another" ( $G 1)$

The responses by the participants below confirm the study of Tahir (2012) that when conducting peer review, students feel less pressure and feel more relax. The students claim that the advices given by peers are very easy to be used specially to revise essay and consider it as very useful. The students are able to engage with more practices and discussions are made among friends through peer review.

... the advices given by the peers would be easy to be understood and they 
understand our capability instead of expecting ...good result from us.

“... from my lecturer and peers' comments, I was told that I have improved a lot overall as compared to my first micro-teaching students will be able to feel more comfortable... because they are receiving comments from their friends. (G2)

"For this time commenting session, the lecturer asked all my classmates to comment... most of them gave me such a great compliment... They said I improved a lot from the previous one". (G2-P3)

\subsubsection{Self- Reflection}

Self-reflection, according to Norberg (2014), helps to construct new and deeper understanding of the experience learnt. It can also improve personal and professional awareness as these responses by the participants confirms the study:

"I think self-reflection is very important... what expects you need to improve and enhance so that you can em... teach better in the classroom" (G2)

"It can help us fix our performance and teaching skills" (G3)

The findings of this study also supports previous study by Toros \& Medar (2015) that claimed that self-reflection promotes constructing new meanings and solutions. As also improves personal and professional awareness and professional growth from learning through experiences. The responses below confirmed the scholars mentioned:

“After reflecting on my mistakes and the audience's comments, I decided to improve my microteaching and do my best to avoid the mistakes $P$ ve done in the first one. During my second micro-teaching, I can feel that I could take control of the class better than the previous time..." (G2-P2).

"During my second session of micro teaching, I came up with solutions to overcome my weaknesses during the previous micro teaching session." (G2-P3)

Langley \& Brown (2010) mentioned that reflective journaling allows students to recognize and record their strengths and weaknesses. It involves an intensely personal process that deals with them in a safe environment. The responses below affirmed the previous study of the scholars mentioned:

"... it is to prove one has done a deep study for she or he knows mistakes that happen during the lesson... allows the students of the course to identify their own mistakes and correct the mistakes for the next time. This allows... oneself to always be careful and aware from making mistakes during the process". (G1)

"you'll be able to know what kind of mistakes and by reflecting to the mistakes they'll be able to improve their teaching quality in the classroom." (G2)

"so, this reflection helps us to identify our own mistakes" (G3)

\subsection{Benefits of Active Learning Strategies}

In the process of making the learning experience enjoyable, the integration of active learning tasks is much appreciated as mentioned by Mocinic (2012) and the response below confirm the findings of this study.

“... the classroom environment will be not so boring" ( $G 2)$ 
The response below also affirms recent study by Freeman et al. (2014) about the importance of learning more about how class time was used and how students perceived the impact of active strategies on their learning.

“... I think active learning strategy is very, very important” (G3)

“... very important... students would be attracted to learn more" (G2)

According to Tedesco-Schneck (2013) the introduction of active learning acts as a path to critical thinking in promoting students' involvement in classroom activities as these responses confirms his study.

“... allows direct interaction between lecturers and students which students hardly do in normal learning session. It promotes open minded ideology because students are able to express opinion. Next, it will enhance communication skill since everyone has to talk using these strategies. Next is, everyone will learn to respect someone else opinion" ( $G 1)$

“... because it allows students to personally engaged with the learning activities" (G2)

“... creates positive learning environment... encourage participation... motivate both sides ... students and teachers" (G3)

\section{Conclusions and Implications of the Study}

\subsection{Conclusions}

In identifying the effectiveness of active learning strategies used in curriculum and pedagogy course employed by a group of undergraduate TESL students, there are three commonly used strategies associated with active learning strategies used in this study which are as follows; micro teaching, peer reflection/ feedback and self-reflection.

The effectiveness of Microteaching can be concluded as follows:

- perceived microteaching as important subject

- help the students of the course to have expectation of what could happen during teaching and learning session

- prepares for real teaching situations

- know how to deal with the students in the classroom

- allows future teachers to be able to familiarise themselves with the teaching practice in the classroom

- help to prepare the lesson beforehand

- increases and improves one confident/teaching quality

- The effectiveness of Peer Reflection/Feedback can be concluded as follows:

- able to know what kind of elements or characteristics that need to improve

- their friends' opinion is very important

- peers know them and their feedbacks help them a lot

- could point their friends' mistakes

- advices given by the peers would be easy to be understood and they understand our capability

- allows students to work professionally among themselves 
- feel more comfortable receiving comments from friends The effectiveness of Self-Reflection can be concluded as follows:

- allows the students to identify their own mistakes and correct the mistakes for the next time

- always be careful and aware from making mistakes during the process.

- very important as what expects need to improve and enhance teaching

- it can help to fix performance and teaching skills

- by reflecting to the mistakes they will be able to improve their teaching quality in the classroom

- came up with solutions to overcome weaknesses during the previous micro teaching session

- take control of the class better than the previous time

From this study, it could not be denied that the findings showed that employing active learning strategies were beneficial as follows:

- the classroom environment will be not so boring and therefore students would be attracted to learn more.

- creates positive learning environment

- it allows direct interaction between lecturers and students which students hardly do in normal learning session.

- it promotes open minded ideology because students are able to express opinion.

- it will enhance communication skill since everyone have to talk contribute feedback

- everyone will learn to respect someone else opinion.

- it allows students to personally engaged with the learning activities.

- encourage participation, motivate both students and teachers.

\subsection{Implications of the Study}

Based on the result derived from this study, it is hoped that it will help the parties involved:

1) Policy Maker

2) Teachers or facilitators

3) Students

Abdullah \& Hui (2014) and many other scholars believe that active learning has a positive influence on student learning outcomes. Therefore, as part of blended learning, a comprehensive structured curriculum that emphasizes more on active learning and student centred approach must be effectively constructed. This will improve the quality of education that deals a lot with the betterment of the teaching and learning process, well-planned curriculum and effective implementation of the curriculum (MOHE, 2007), as this objective has been highlighted in the National Higher Education Strategic Plan 2020, which then later becomes one of the key performance indicators for the implementation of the strategic plan (MOHE, 2007) of higher education. Furthermore, the study also 
indicates that the active learning approach has proven to be beneficial to students in higher education especially among future teachers of tomorrow.

As for teachers or facilitators, they could identify the students' learning styles and apply these best practices in this curriculum and pedagogy course. They can guide their students to impart active learning strategies in the course and assist them to utilise other active learning strategies available apart from these three.

Last but not least, the findings will provide the students with better guidance for utilising and maximizing different other selections of active learning strategies that could benefit their teaching and learning process. The benefits of active learning strategies will be the platform for students to gain a better understanding also as an exposure to be trained properly and competently enough as future teachers. It is also hoped that these soon to be English teachers no longer classified as "incapable" or "unfit" to teach the subject in schools.

\section{References}

Abdullah, Z., \& Hui, J. (2014). The Relationship between Communication Satisfaction and Teachers' Job Satisfaction in the Malaysian Primary School. Asian Journal of Humanities and Social Sciences (AJHSS), 2, 58-71. http://ajhss.org/pdfs/Vol2Issue2/7.pdf

Azizan, F. Z. (2010). Blended Learning in Higher Education Institution in Malaysia. In Proceedings of Regional Conference on Knowledge Integration in ICT (pp. 454-466). https://pdfs.semanticscholar.org/9c32/77d83acc61d0f30d79c8dd4a999720d38b3c.pdf

Chamhuri, S., \& Abdul-Mumin, A. (2011). Education as a Catalyst towards Realising the Development Goals of Malaysia: Case Study of the East Coast Economic Study of the East Coast Economic Region. 0011-0019. In 5th International Conference on Technology, Education and Development. http://irep.iium.edu.my/8847/1/SPAIN\%27S_CONFERENCE_PROCEEDINGS--VAL ENCIA_edu-ecer_-2011.pdf

Creswell, J. W. (2014). Educational Research: Planning, Conducting and Evaluating Quantitative and Qualitative Research (4th ed.). Harlow: Pearson. http://basu.nahad.ir/uploads/creswell.pdf

Dale, E. (1969). Audio-Visual Methods in Teaching (3rd ed., p. 108). Holt, Rinehart \& Winston, New York: Dryden Press.

https://www.researchgate.net/figure/283011989_fig1_Figure-2-Edgar-Dale-Audio-Visu al-Methods-in-Teaching-3rd-Edition-Holt-Rinehart-and

Dzakiria, H., Don, M. S., \& Rahman, H. D. A. (2012). Blended Learning (BL) as Pedagogical Alternative to Teach Business Communication Course: Case Study of UUM Executive Diploma Program. Turkish Online Journal of Distance Education, 13, 297-315. http://dergipark.ulakbim.gov.tr/tojde/article/view/5000102354

Fernandez, M. L. (2010). Investigating How and What Prospective Teachers Learn through Microteaching Lesson Study. Teaching and Teacher Education, 26, 351-362. http://project8020.weebly.com/uploads/2/6/7/6/2676617/fernandez2010.pdf https://doi.org/10.1016/j.tate.2009.09.012

Fisher, K. (2010). Technology-Enabled Active Learning Environments: An Appraisal CELE Exchange. Location: Centre of Effective Learning Environments.

Freeman, S., Eddy, S. L., McDonough, M., Smith, M. K., Okoroafor, N., Jordt, H., \& Wenderoth, M. P. (2014). Active Learning Increases Student Performance in Science, Engineering, and Mathematics. Proceedings of the National Academy of Sciences of 
the United States of America, 111, 8410-8415.

http://www.pnas.org/content/111/23/8410.full https://doi.org/10.1073/pnas.1319030111

Ghanaguru, S., Nair, P., \& Yong, C. (2013). Teacher Trainers' Beliefs in Microteaching and Lesson Planning in a Teacher Training Institution. The English Teacher, 42, 216.

Ingersoll, R. M., \& Strong, M. (2011). The Impact of Induction and Mentoring Programs for Beginning Teachers: A Critical Review of the Research. Review of Educational Research, 81, 201-233. https://doi.org/10.3102/0034654311403323

Ismail, S. A. A. (2011). Student Teachers' Microteaching Experiences in a Preservice English Teacher Education Program. Journal of Language Teaching and Research, 2, 1043-1051. http://www.academypublication.com/issues/past/jltr/vol02/05/13.pdf

Langley, M. E., \& Brown, S. T. (2010). Perceptions of the Use of Reflective Learning Journals in online graduate nursing education. Nursing Education Perspective, 31, 12-17.

Malaysia Education Blueprint 2013-2025 (MOE, 2012). https://www.moe.gov.my/images/dasar-kpm/articlefile_file_003108.pdf

Meerah, T. S. M., Halim, L., \& Nadeson, T. (2010). Environmental Citizenship: What Level of Knowledge, Attitude, Skill and Participation the Students Own? Procedia-Social and Behavioral Sciences, 2, 5715-5719. https://doi.org/10.1016/j.sbspro.2010.03.933

Ministry of Higher Education (MOHE) (2007). National Higher Education Action Plan 2007-2010: Triggering Higher Education Transformation.

http://planipolis.iiep.unesco.org/sites/planipolis/files/ressources/malaysia_higher_educ ation_action_plan_2007-2010.pdf

Močinić, S. N. (2012). Active Teaching Strategies in Higher Education. Metodičkiobzori, 15. https://pdfs.semanticscholar.org/ba81/14104a900eb9b0240b02d9edf4f72bb22d18.pdf

Norberg, U. (2014). Fostering Self-Reflection in Translation Students: The Value of Guided Commentaries. Translation and Interpreting Studies, 9, 150-164. https://doi.org/10.1075/tis.9.1.08nor

Remesh, A. (2013). Microteaching, an Efficient Technique for Learning Effective Teaching. Journal of Research in Medical Sciences, 18, 158-163.

https://www.researchgate.net/profile/DrAmbili_Remesh/publication/255178973_Micro teach-

ing_an_efficient_technique_for_learning_effective_teaching/links/53cef8ad0cf2f7e53cf 7e49e/Microteaching-an-efficient-technique-for-learning-effective-teaching.pdf

Shiu, A., Chan, C., Lam, P., Lee, J., \& Kwong, A. (2012). Baccalaureate Nursing Students' Perceptions of Peer Assessment of Individual Contributions to a Group Project: A Case Study. Nurse Education Today, 32, 214-218. https://doi.org/10.1016/j.nedt.2011.03.008

Strijbos, J. W., \& Sluijsmans, D. (2010). Unravelling Peer Assessment: Methodological, Functional, and Conceptual Developments. Learning and Instruction, 20, 265-269.

https://hal.archives-ouvertes.fr/hal-00703895/document https://doi.org/10.1016/j.learninstruc.2009.08.002

Tahir, I. H. (2012). A Study on Peer Evaluation and Its Influence on College ESL Students. Procedia-Social and Behavioral Sciences, 68, 192-201. http://www.sciencedirect.com/science/article/pii/S1877042812057023 https://doi.org/10.1016/j.sbspro.2012.12.219

Tedesco-Schneck, M. (2013). Active Learning as a Path to Critical Thinking: Are Competencies a Roadblock? Nurse Education in Practice, 13, 58-60.

https://doi.org/10.1016/j.nepr.2012.07.007 
Toros, K., \& Medar, M. (2015). Social Work Students' Thoughts on Self-Reflection: A Qualitative Study Based on Reflective Journaling. International Journal of Humanities and Social Science, 5, 89-96.

http://www.ijhssnet.com/journals/Vol_5_No_3_March_2015/11.pdf

Yahyazade, M., Moghaddam, M. M., \& Attaran, A. (2014). Towards an Interactive EFL Class: Using Active Learning Strategies. International Journal of Modern Education and Computer Science, 6, 8. https://doi.org/10.5815/ijmecs.2014.05.02

Yin, R. K. (2011). Qualitative Research from Start to Finish. Guilford Publications.

Zakaria, W. Z. B. W., \& Ah'hyat, N. A. B. (2010). A Study on Microteaching as Perceived by UTM TESL Undergraduates. https://core.ac.uk/download/pdf/11786974.pdf http://www.thestar.com.my/news/nation/2013/09/11/idris-many-teachers-not-fit-to-te ach-70-of-english-instructors-found-to-be-incapable-says-education/ 